\title{
SOLVENT OPTIMIZATION OF ELECTROSPUN POLY(ACRYLIC ACID) NANOFIBERS
}

\section{DOI: 10.35530/TT.2021.27}

\author{
M. Geysoğlu ${ }^{1 *}$, F.C. Çallığglu² \\ ${ }^{1}$ Bioengineering Department, Institute of Natural and Applied Sciences, Süleyman Demirel University, \\ Turkey \\ (E-mail: mustafageysoglu@sdu.edu.tr) \\ ${ }^{2}$ Textile Engineering Department, Engineering Faculty, Süleyman Demirel University, Turkey \\ (E-mail: fundacengiz@sdu.edu.tr)
}

\begin{abstract}
In this study, it was investigated experimentally the influence of various solvents (distilled water and ethanol) on the solution properties, spinning performance, and fibre morphology of the electro spun Poly (acrylic acid) nanofibers. Firstly, polymer solutions were prepared at $5 \mathrm{wt} \%$ PAA with various solvent ratios of ethanol and distilled water. Then, solution properties such as viscosity, density, $\mathrm{pH}$, conductivity, and surface tension were determined. The production of nanofiber samples was carried out by electrospinning under the optimum process parameters (voltage, distance between electrodes, feed rate, and atmospheric conditions). Finally, the morphological characterization of the nanofiber surface was carried out with SEM. According to the results, it was observed that conductivity, surface tension and the density of the solution increase as the ethanol ratio decreases. On the other hand, $p H$ value increases as the ethanol ratio increases and, so, the acidic value of the solutions decreases. The viscosity increased until the ethanol/distilled water ratio was 50/50 and then decreased as the ethanol percentage decreased to under 50\%. In addition, average fibre diameter decreases with ethanol ratio decreases. It is possible to say that solvent type affects solution properties, fibre morphology and spinning performance significantly. Generally, fine, uniform and bead free nanofibers could be electro spun and the PAA solution containing $70 \mathrm{wt} \%$ distilled water and $30 \mathrm{wt} \%$ ethanol was selected as the optimum in terms of fibre morphology, web quality and spinning performance.
\end{abstract}

Keywords: electrospinning, ethanol, nanofiber, poly(acrylic acid), solvent optimization

\section{INTRODUCTION}

In this study, it was aimed at achieving electrospinning of Poly (acrylic acid) (PAA) nanofibers with various solvents such as distilled water and ethanol. It is known from the literature that these solvents can be used to solve PAA separately or together [13].

PAA is a superabsorbent, water soluble, innocuous [4], synthetic, and high molecular weight polymer of acrylic acid [3]. PAA is also non-toxic and very sensitive to temperature and $\mathrm{pH}$ changes. Therefore, PAA has attracted great interest in different fields, especially biomedical applications [5].

Nanofibers have unequalled properties, such as very small fibre diameter, high porosity, small controllable pore size, very high specific surface area $\left(\mathrm{m}^{2} / \mathrm{g}\right)$ etc. [6]. Thanks to their unique features, nanofibers can be a promising material for a variety of applications, from medical to consumer products, and industrial to high-tech applications. In literature, there are several studies on the medical application areas of PAA based 
nanofibers, such as drug delivery [7,8], tissue engineering, implant coatings, wound dressing [9], etc.

Solvent selection is an important step in obtaining uniform and fine nanofibers by electrospinning. There are some studies about solvent optimization and solvent effects on solution properties and fibre morphology in literature. Yang et al. investigated the influence of solvents on the morphology of the poly (vinylpyrrolidone) (PVP) nanofibers prepared by electrospinning with different solvents, including ethanol, dichloromethane, and dimethylformamide, and they specified that solution properties and fiber morphology were affected by solvent type [10]. Gee et al. compared the effects of three solvents (dimethylformamide, N-methylpyrrolidone, and dimethyl sulfoxide) on fiber formation. These researchers also observed that fiber morphology, such as fiber diameters, web thickness, and pore area, were affected by solvent ratio [11].

This study aims to analyse the effect of ethanol and distilled water on PAA-based nanofiber morphology and contribute to the literature.

\section{MATERIALS AND METHODS}

For this study, PAA was used as a polymer. Distilled water and ethanol were used as the solvents to obtain nanofibrous surfaces. PAA with a viscosity-average molecular weight of 450,000 was purchased from Sigma-Aldrich (St. Louis, MO, USA) and ethanol was purchased from ISOLAB (Izmir, Turkey). The PAA polymer concentration was kept constant at $5 \mathrm{wt} \%$ and details of solvent ratios are given below in Table 1.

Table 1. Different solvents ratios of PAA solutions with sample codes

\begin{tabular}{|c|c|c|}
\hline $\begin{array}{c}\text { Sample } \\
\text { Codes }\end{array}$ & $\begin{array}{c}\text { Distilled } \\
\text { Water Ratio (wt\%) }\end{array}$ & $\begin{array}{c}\text { Ethanol } \\
\text { Ratio (wt \%) }\end{array}$ \\
\hline S1 & 0 & 100 \\
\hline S2 & 10 & 90 \\
\hline S3 & 30 & 70 \\
\hline S4 & 50 & 50 \\
\hline S5 & 70 & 30 \\
\hline S6 & 90 & 10 \\
\hline S7 & 100 & 0 \\
\hline
\end{tabular}

It is known from the literature that process parameters of electrospinning, such as applied voltage, solvent selection, distance between needle and collector, solution flow rate, etc., have to be optimized to obtain uniform, fine, and bead-free nanofibers [3]. All process parameters were kept constant except solvent ratios during the spinning process.

The study consists of three stages. In the first stage, PAA solution properties such as viscosity, conductivity, $\mathrm{pH}$, surface tension, and solution density were measured. At the second stage, a needle electrospinning process using optimum process parameters carried out nanofiber production. During the nanofiber production process, $14 \mathrm{kV}$ voltage, 0.6 $\mathrm{ml} / \mathrm{h}$ solution feed rate, and $22.5 \mathrm{~cm}$ distance between the electrodes were applied for all solutions. Also, spinning experiments were achieved under ambient conditions of $32 \%$ $( \pm 1)$ humidity and $25^{\circ} \mathrm{C}( \pm 1)$ degree temperature for all samples. All nanofibers were produced for 20 minutes and collected on an alumina foil.

The last step of the study is the characterization of PAA nanofibers in terms of fibre diameter, fibre diameter uniformity, and web surface structure (bead, stickiness etc.). The morphology was analysed with a Scanning Electron Microscope (SEM). By using image $\mathrm{J}$ analysing software, the average fibre diameters were calculated. The findings 
were analysed statistically with the SPSS analysis program. The fibre uniformity coefficient was calculated using equations 1 and 2 which are given below [12]:

$$
\begin{aligned}
& \boldsymbol{A}_{\boldsymbol{n}}=\frac{\sum n_{i} d_{i}}{\sum n_{i}} \text { (number average) } \\
& \boldsymbol{A}_{\boldsymbol{w}}=\frac{\sum n_{i} d_{i}^{2}}{\sum n_{i} d_{i}} \text { (weight average) }
\end{aligned}
$$

where $d_{i}$ is fibre diameter and ni - fibre number.

The fibre diameter uniformity coefficient was determined by the ratio of $A_{w} / A_{n}$ and optimum value should be very close to 1 for uniform fibres.

\section{RESULTS AND DISCUSSIONS}

\subsection{Solution Properties}

From the solution results are given in figure 1, it was observed that conductivity, surface tension, and the density of the solution increase as the ethanol ratio decreases.
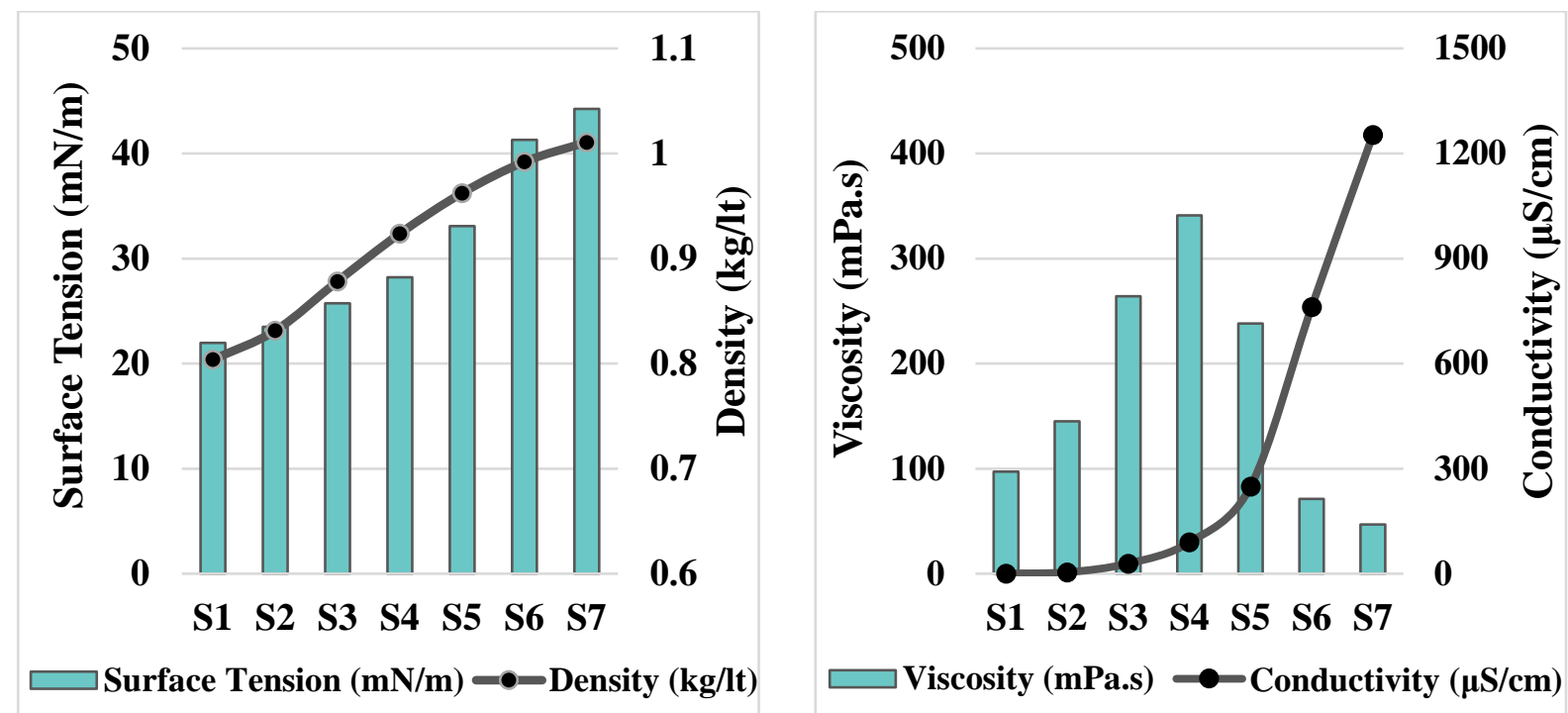

Figure 1. Results of solution properties such as surface tension, density, viscosity and conductivity of PAA with various solvent ratios

On the other hand, $\mathrm{pH}$ value increases as the ethanol ratio increases and, so, the acidic value of the solutions decreases. The viscosity increased until the ethanol/distilled water ratio was 50/50 and then decreased as the ethanol percentage decreased to under 50\%. The viscosity has the highest value where the solvent ratios are equalized (S4).

\subsection{Fiber Morphology}

SEM pictures of PAA nanofibers with different solvents ratios of distilled water and ethanol are given in figure 2. Spinning could not be achieved with PAA solutions include only distilled water (S1) and only ethanol (S7) as a solvent. 

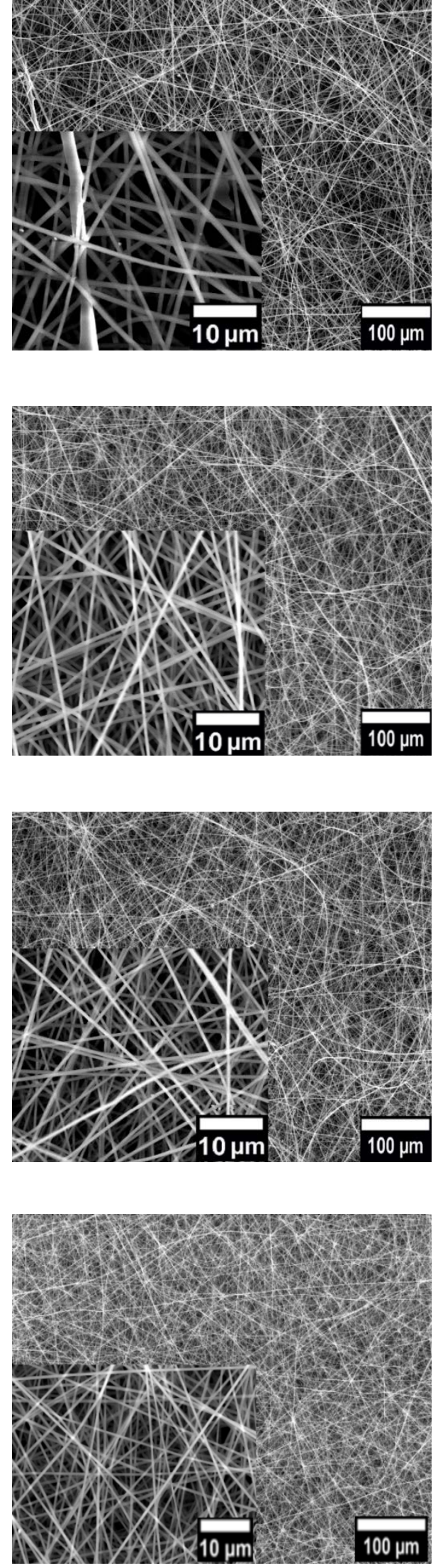

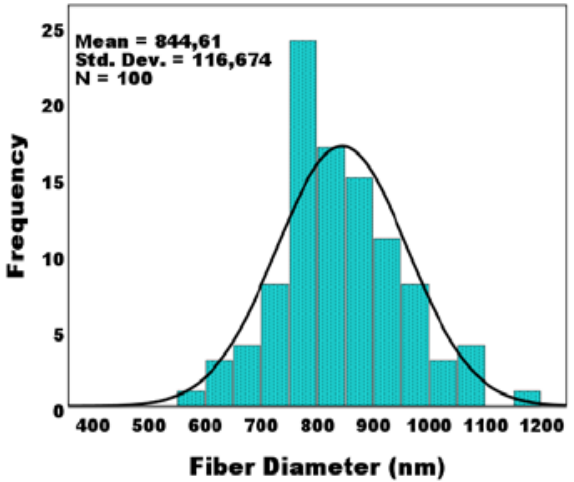

(S2)

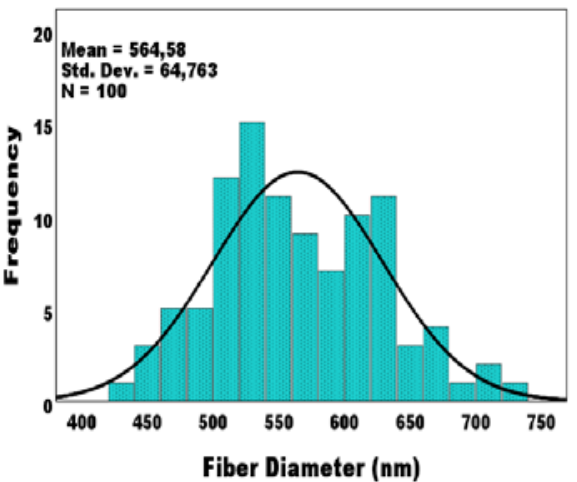

(S3)

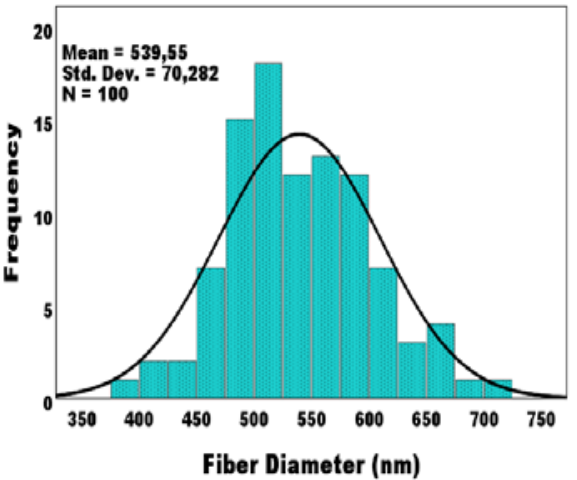

(S4)

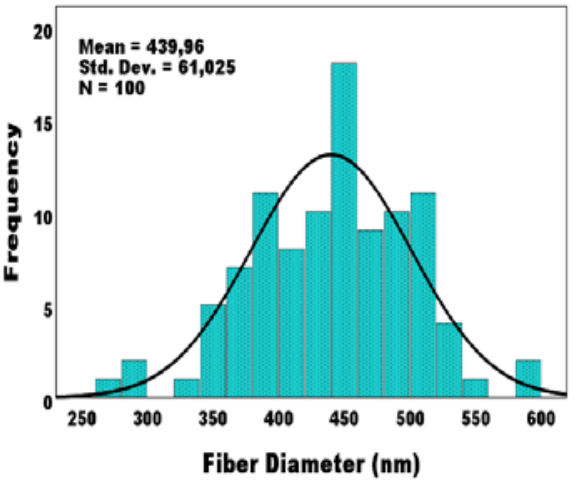

(S5) 

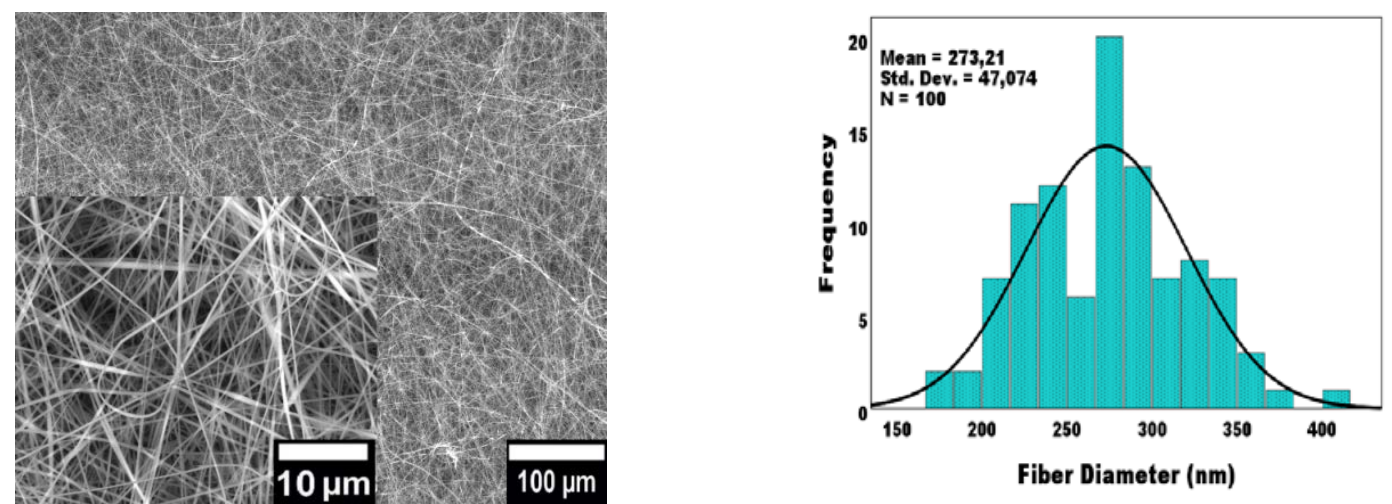

(S6)

Figure 2. SEM images and fibre diameter histograms of PAA nanofibers (1.000x, $10.000 \mathrm{x}$ ) produced with different solvents ratios of distilled water and ethanol.

It was clearly observed from the SEM images that generally, uniform and smooth nanofibers were produced and unimodal histogram curves were obtained. In addition, all fibre structures are bead-free and bead formation was not observed with the change of solvent ratio.

The effect of different solvent ratios on the average fibre diameter and fibre diameter uniformity coefficient was shown in Figure 3.

According to Figure 3, it was determined that average fibre diameter decreased as the ethanol concentration decreased. This result is compatible with solution properties and literature [2]. The finest fibres were obtained from an S6 sample (273 nm) including $10 \mathrm{wt} \%$ ethanol. Fibre diameter uniformity coefficient values are very close to 1 for all samples and the most uniform sample is S3 with a 1.013 value. It is possible to say that uniform, smooth nanofibers, good web quality without beads and unimodal fibre diameter histograms were obtained.

The PAA solution containing $70 \mathrm{wt} \%$ distilled water and $30 \mathrm{wt} \%$ ethanol (S5) was selected as the optimum in terms of fibre morphology, web quality, and spinning performance. From the calculations, it was specified that the average fibre diameter is $440 \mathrm{~nm}$ and the fibre diameter uniformity coefficient is 1.019. 


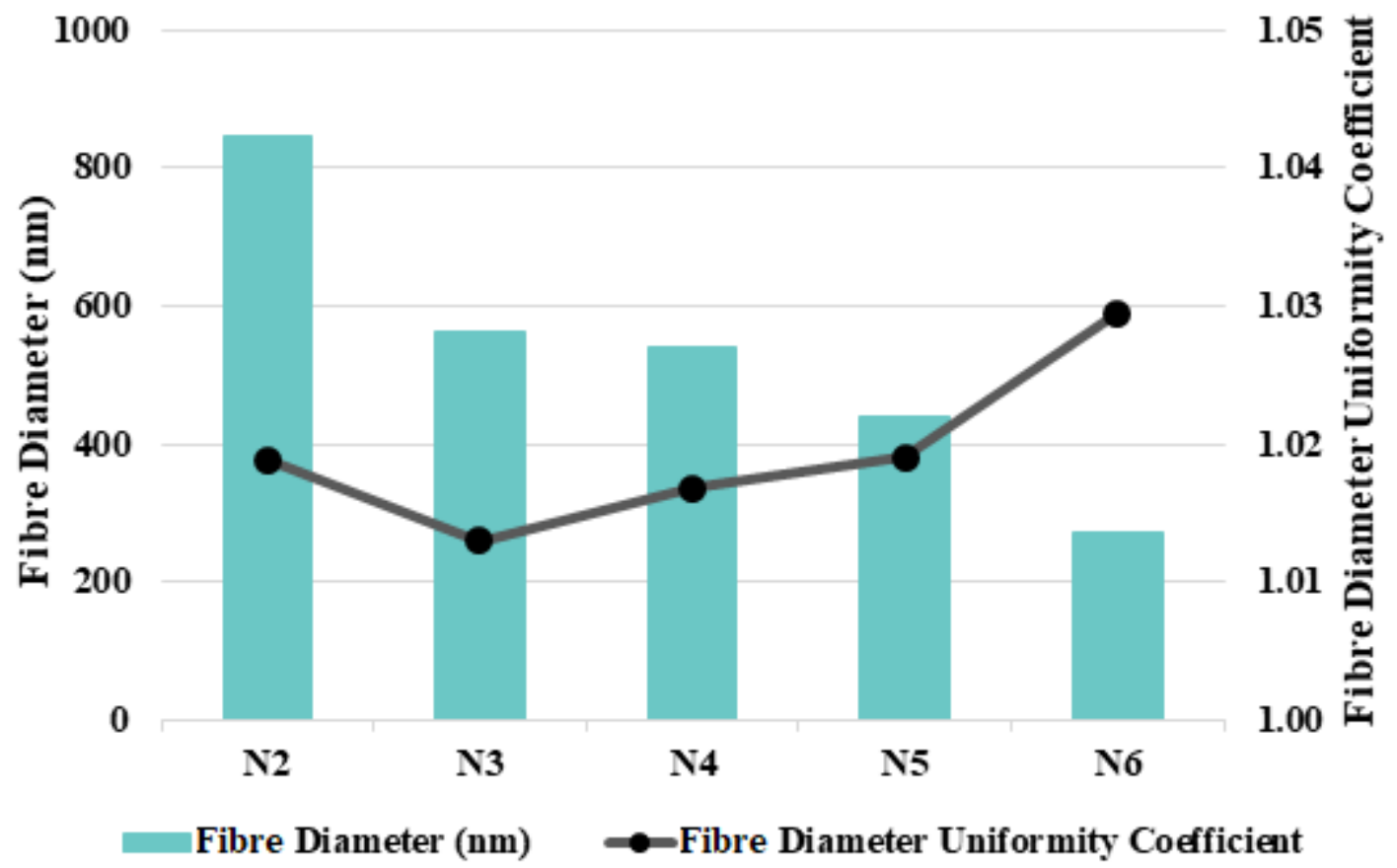

Figure 3. The effect of different solvent ratios on the average fibre diameter and fibre diameter uniformity coefficient

\section{CONCLUSION}

The production and characterization of PAA nanofibers prepared with different solvent ratios were achieved in this study. From the results, it is clearly seen that solvent type affects solution properties, fibre morphology and spinning performance distinctively. After the analysis of all the results, the PAA solution containing $70 \mathrm{wt} \%$ distilled water and $30 \mathrm{wt} \%$ ethanol was selected as the optimum in terms of fibre morphology, web quality, and spinning performance.

\section{ACKNOWLEDGMENT}

The authors would like to express appreciation for the financial support of the Süleyman Demirel University Scientific Researches Project Unit [Project Number $=$ FDK2019-7164].

\section{REFERENCES}

[1] Kim, B., Park, H., Lee, S., et al., Poly(acrylic acid) nanofibers by electrospinning, In: Mater. Lett., 2005, 59, 829-832, https://doi.org/10.1016/j.matlet.2004.11.032

[2] Theron, S.A., Zussman, E., Yarin, A.L., Experimental investigation of the governing parameters in the electrospinning of polymer solutions, In: Polymer, 2004, 45, 6, 2017-2030, https://doi.org/10.1016/j.polymer.2004.01.024

[3] Khampieng, T., Wnek, G.E., Supaphol, P., Electrospun DOXY-h loaded-poly(acrylic acid) nanofiber mats: in vitro drug release and antibacterial properties investigation, In: J. Biomater. Sci. Polym. Ed., 2014, 25, 12, 1292-1305, http://dx.doi.org/10.1080/09205063.2014.929431

[4] Shukla, N.B., Darabonia, N., Madras, G., Ultrasonic degradation of poly(acrylic acid), In: J. Appl. Polym. Sci., 2009, 112, 2, 991-997, https://doi.org/10.1002/app.29460 
[5] Chen, K., Wang, S., Guo, X., Confinement effect on the aqueous behaviors of free poly(acrylic acid) and poly(acrylic acid) grafted on a nanoparticle surface, In: Colloid Polym. Sci., 2019, 297, 1223-1231, https://doi.org/10.1007/s00396-019-04541-2

[6] Bhardwaj, N., Kundu S.C., Electrospinning: a fascinating fiber fabrication technique, In: Biotechnol. Adv., 2010, 28, 3, 325-347, https://doi.org/10.1016/j.biotechadv.2010.01.004

[7] Velasco-Barraza, R.D., Vera-Graziano, R., López-Maldonado, E.A., et al., Study of nanofiber scaffolds of PAA, PAA/CS, and PAA/ALG for its potential use in biotechnological applications, In: Int J Polym Mater., 2018, 67, 13, 800-807, https://doi.org/10.1080/00914037.2017.1378887

[8] Chunder, A., Sarkar, S., Yu, Y., et al., Fabrication of ultrathin polyelectrolyte fibers and their controlled release properties. In: Colloids Surf. B Biointerfaces, 2007, 58, 172-179, https://doi.org/10.1016/j.colsurfb.2007.03.004

[9] Bandeira, M., Chee, B.S., Frassini, R., et al., Antimicrobial PAA/PAH Electrospun Fiber Containing Green Synthesized Zinc Oxide Nanoparticles for Wound Healing. In: Materials, 2021, 14, 2889, https://doi.org/10.3390/ma14112889

[10] Yang, Q., Li, Z., Hong, Y., et al., Influence of solvents on the formation of ultrathin uniform poly(vinyl pyrrolidone) nanofibers with electrospinning, In: J. Polym. Sci. B Polym. Phys., 2004, 42, 3721-3726, https://doi.org/10.1002/polb.20222

[11] Gee, S., Johnson, B., Smith, A.L., Optimizing electrospinning parameters for piezoelectric PVDF nanofiber membranes, In: J. Membr. Sci,, 2018, 563, 804-812, https://doi.org/10.1016/j.memsci.2018.06.050

[12] Cengiz, F., Jirsak, O., The Effect of Salt on the Roller Electrospinning of Polyurethane Nanofibers, In: Fibers Polym., 2009, 10, 2, 177-184, https://doi.org/10.1007/s12221-009-0177-7 